\title{
A Sensitive Voltammetric Determination of Anti-Parkinson Drug Pramipexole Using Titanium Dioxide Nanoparticles Modified Carbon Paste Electrode
}

\author{
Seyed Karim Hassaninejad-Darzi* and Farshad Shajie \\ Research Laboratory of Analytical \& Organic Chemistry, Department of Chemistry, Faculty of \\ Science, Babol University of Technology, P.O.Box 47148-71167 Babol, Iran
}

\begin{abstract}
In this study, a facile sensor based on $\mathrm{TiO}_{2}$ nanoparticles modified carbon paste electrode was developed for voltammetric determination of pramipexole in pharmaceutical formulations and biological samples. Surface of the fabricated electrode have been characterized using field emission scanning electron microscopy. Under the optimized experimental conditions, the modified electrode was exhibited excellent electrocatalytic activities and a sensitive oxidation peak at $0.9 \mathrm{~V}$ in the phosphate solution of $\mathrm{pH} 5.0$ for electrooxidation of pramipexole. The plot of $\mathrm{pH} v \mathrm{~s} . \mathrm{E}_{\mathrm{p}}$ generated a slope of $62.5 \mathrm{mV}$ per $\mathrm{pH}$ in the $\mathrm{pH}$ range of 3.0-13.0 indicating the contribution of an equal number of electrons and protons in the electrode process. A differential pulse voltammetry method was developed in the concentration range of $0.46-100 \mu \mathrm{mol} \mathrm{L}^{-1}$ with a limit of detection of $0.14 \mu \mathrm{mol} \mathrm{L} \mathrm{L}^{-1}$. The proposed method is simple, rapid, and inexpensive and also showed good selectivity and sensitivity toward pramipexole.
\end{abstract}

Keywords: pramipexole, $\mathrm{TiO}_{2}$ nanoparticles, modified CPE, differential pulse voltammetry, electroanalysis

\section{Introduction}

Parkinson's disease is a common neurodegenerative disorder disease; it affects few parts of the brain which controls vital muscle movement. Pramipexole dihydrochloride monohydrate (PRX) is a widely preferred drug for the treatment of Parkinson's disease, since it has a direct activity on the central nervous system. ${ }^{1} \mathrm{PRX}$, chemically known as (6S)-N6-propyl-4,5,6,7-tetrahydro1,3-benzothiazole-2,6-diamine, is a dopaminergic agonist drug and the chemical structure is shown in Scheme 1. It has the capability to excite dopamine receptors in the striatum and is used for the treatment of depressive syndromes. ${ }^{2,3}$ Since 1997, the US government has approved the PRX

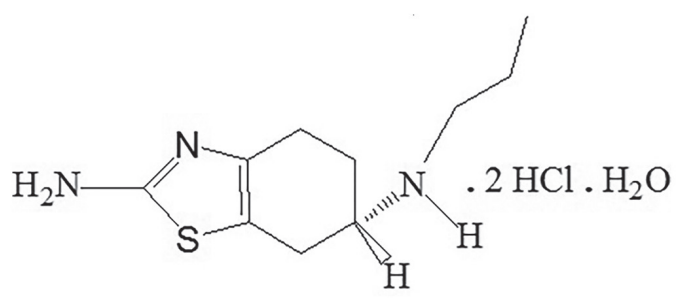

Scheme 1. Chemical structure of PRX.

*e-mail: hassaninejad@nit.ac.ir drug to treat Parkinson's disease; the healing importance of PRX has made researchers to develop sensitive, selective, reliable and rapid analytical methods.

There are many methods currently available for the determination of PRX such as UV-Vis spectrophotometry, ${ }^{4}$ high-performance liquid chromatography (HPLC) with ultraviolet and electrochemical detection, ${ }^{5}$ high-performance liquid chromatography-mass spectrometry (HPLC-MS), ${ }^{6}$ HPLC with Monte Carlo simulations, ${ }^{7}$ spectrophotometry method based on the diazotization of primary amine group of pramipexole, ${ }^{8}$ gas chromatography mass spectrometry (GC-MS), ${ }^{9}$ thin layer chromatography ${ }^{10}$ and capilary electrophoresis with laser induced fluorescence detection. ${ }^{11}$ Furthermore, the above mentioned methods such as chromatographic methods require expensive instruments, organic solvents, reagents for the extraction and often time-consuming and hence, sensitive, reliable, and simple analytical methods were required to determine PRX. ${ }^{12}$

In the field of analytical chemistry, electrochemical methods have been widely attracted due to higher reliability, simplicity, rapid detection, high sensitivity and possibility of miniaturization. ${ }^{13}$ Metal nanoparticles are very increasingly used for the electrode modification due to their extraordinary catalytic activities over corresponding 
bulk metal electrodes. ${ }^{14}$ The unique chemical and physical properties of nanoparticles make them extremely suitable for designing and improving sensing devices, especially electrochemical and biosensors. Different kinds of nanomaterials, such as metals, metal oxides, carbon based materials and semiconductor nanoparticles, have been used for constructing electrochemical sensors and biosensors. ${ }^{15}$ $\mathrm{TiO}_{2}$ nanoparticles have excellent chemical and physical properties; they have been used in the sensor preparation, coating, solar cell, and photocatalyst applications. ${ }^{16,17}$ These nanoparticles have been incorporated with other compounds, such as graphite and carbon nanotubes, to make modified electrodes in the electrochemical analysis of some biological compounds, ${ }^{18-22}$ because they provide more active sites at the surface of the electrode. $\mathrm{TiO}_{2}$ nanoparticles can be used in wide potential windows and improve the stability of the electrode, therefore, increase the repeatability of the electrode response. The carbon paste electrodes (CPEs) are very popular due to their wide anodic potential range, low residual current, ease of fabrication, easy renewal and low cost. ${ }^{23}$

Up-to-date, no voltammetric procedure was described using a carbon paste electrode modified with $\mathrm{TiO}_{2}$ nanoparticles for the quantification of PRX drug in the pharmaceutical or biological samples. In the present study, we fabricated a new sensor based on $\mathrm{TiO}_{2}$ nanoparticles modified carbon paste electrode $\left(\mathrm{TiO}_{2} \mathrm{NPs} / \mathrm{CPE}\right)$ for the electrochemical determination of PRX.

\section{Experimental}

\section{Reagents and materials}

All utilized materials were of analytical reagent grade and used as purchased, without further purification and all solutions were prepared freshly with deionized water. Pramipexole dihydrochloride monohydrate ( $>95 \%$ purity) and $\mathrm{TiO}_{2}$ nanoparticle (nanoparticles ca. $21 \mathrm{~nm},>99.5 \%$ ) were purchased from Sigma-Aldrich (St. Louis, MO, USA). Two series of pramipexole tablet containing different doses ( $0.35 \mathrm{and} /$ or $0.7 \mathrm{mg}$ ) were obtained from Dr. Abidi pharmaceutical company (Tehran, Iran). Graphite powder and paraffin oil $\left(\mathrm{d}=0.88 \mathrm{~g} \mathrm{~cm}^{-3}\right)$ as the binding agent (both from Daejung company, Shiheung, Korea) were used for preparing the paste. The biological samples used in this work were obtained from Blood Transfusion Organization (Babol, Iran). Potassium chloride from Fluka (Buchs, Switzerland) was used as the supporting electrolyte. Potassium ferricyanide $\left(\mathrm{K}_{4} \mathrm{Fe}(\mathrm{CN})_{6}\right)$ was purchased from Merck company (Merck, Darmstadt, Germany) and used as the standard redox system.

\section{Apparatus}

The morphology of the modified electrode $\left(\mathrm{TiO}_{2} \mathrm{NPs} / \mathrm{CPE}\right)$ was obtained using field emission scanning electron microscopy (FESEM) on a MIRA 3 XM TESCAN instrument with the operation of $5.0 \mathrm{kV}$. A digital $\mathrm{pH}$ meter (Hana, USA) was used to read the $\mathrm{pH}$ of the solutions. The electrochemical experiments were performed at room temperature using potentiostat/galvanostat electrochemical analyzer (SAMA500, Iran) with a voltammetry cell in a three electrodes configuration. The platinum wire and $\mathrm{Ag}|\mathrm{AgCl}| \mathrm{KCl}\left(3 \mathrm{~mol} \mathrm{~L}^{-1}\right)$ were used as auxiliary and reference electrodes, respectively. The bare $\mathrm{CPE}$ and $\mathrm{TiO}_{2}$ nanoparticles modified $\mathrm{CPE}\left(\mathrm{TiO}_{2} \mathrm{NPs} / \mathrm{CPE}\right)$ were used as the working electrodes.

\section{Preparation of the working electrode}

In a typical electrode preparation, diethyl ether was added to a mixture of $0.03 \mathrm{~g} \mathrm{TiO}_{2} \mathrm{NPs}$ and $0.17 \mathrm{~g}$ of graphite powder. After hand mixing with a mortar and pestle, the solvent was evaporated with stirring. Then, paraffin oil (35 wt.\%) was blended with the mixture in a mortar by hand mixing for 30 min until a uniformly wetted paste was obtained. This paste was packed into the end of a glass tube (ca. $0.35 \mathrm{~cm}$ i.d. and $10 \mathrm{~cm}$ long) and the copper wire was utilized for electrical contact. A new surface was achieved by pushing an excess of the paste out of the tube and polishing with a weighing paper. For comparison, bare $\mathrm{CPE}$ was also prepared in the same way in the absence of $\mathrm{TiO}_{2} \mathrm{NPs}$.

\section{Analytical procedure}

A series of phosphate solutions $\left(0.1 \mathrm{~mol} \mathrm{~L}^{-1}\right)$ in the $\mathrm{pH}$ range of 3.0-13.0 were prepared by mixing stock solutions of $0.1 \mathrm{~mol} \mathrm{~L}^{-1} \mathrm{H}_{3} \mathrm{PO}_{4}, \mathrm{KH}_{2} \mathrm{PO}_{4}, \mathrm{~K}_{2} \mathrm{HPO}_{4}$ and $\mathrm{K}_{3} \mathrm{PO}_{4}$, and used as supporting electrolytes. A stock solution of $1.0 \times 10^{-2} \mathrm{~mol} \mathrm{~L}^{-1}$ pramipexole was prepared daily by dissolving $0.1056 \mathrm{~g}$ pramipexole in $50 \mathrm{~mL}$ water and then stored at $4{ }^{\circ} \mathrm{C}$. Standard solutions were prepared using this stock solution by accurate dilution with water in the proposed concentration range $\left(0.46-100 \mu \mathrm{mol} \mathrm{L}^{-1}\right)$. The working solutions were prepared by mixing appropriate volume of stock solution, phosphate solutions and $1 \mathrm{M} \mathrm{KCl}$ as supporting electrolyte. The differential pulse voltammograms (DPVs) were recorded by applying positive potential scan from $0.0-1.5 \mathrm{~V} v s . \mathrm{Ag}|\mathrm{AgCl}| \mathrm{KCl}\left(3 \mathrm{~mol} \mathrm{~L}^{-1}\right)$, and pulse amplitude and scan increment of 50 and $25 \mathrm{mV} \mathrm{s}^{-1}$, respectively. All voltammetric measurements were carried out at ambient temperature. 


\section{Assay of the PRX in tablets}

The contents of ten tablets were finely crushed with mortar and pestle to form a fine homogenous powder. Subsequently, a quantity equivalent to one tablet was collected and dissolved in a $100 \mathrm{~mL}$ volumetric flask with deionized water and sonicated for $15 \mathrm{~min}$. The samples from the clear liquor were withdrawn and quantitatively diluted with the selected supporting electrolyte $\left(0.1 \mathrm{~mol} \mathrm{~L}{ }^{-1}\right.$ phosphate solution, $\left.\mathrm{pH}=5.0\right)$. The content of the drug in the tablet was determined by referring to the calibration graph or regression equation and recovery percentages were calculated to examine the accuracy of the proposed method.

\section{Determination of PRX in human plasma samples}

Serum samples obtained from healthy individuals (after having obtained their written consent) were stored frozen until use. For the assay of PRX in plasma, $500 \mu \mathrm{L}$ PRX solution $\left(10 \mu \mathrm{mol} \mathrm{L} \mathrm{L}^{-1}\right)$ was added to $500 \mu \mathrm{L}$ of untreated plasma and the mixture was vortexed for $30 \mathrm{~s}$. In order to precipitate the plasma proteins, the plasma samples were treated with $250 \mu \mathrm{L}$ perchloric acid (15\%) and then, the mixture was centrifuged at $6000 \mathrm{rpm}$ for $10 \mathrm{~min}$. An appropriate volume of the supernatant liquor was transferred into the voltammetric cell containing phosphate solution of $\mathrm{pH} 5.0$ and DPVs were recorded. The content of the PRX in the plasma was measured referring to the calibration graph or regression equation.

\section{Results and Discussion}

\section{Physical characterization of the modified electrode}

The SEM image provides useful approach to the determination of size, morphology and surface of the modified electrode. Figures $1 \mathrm{a}$ and $1 \mathrm{~b}$ show the scanning electron micrographs of $\mathrm{CPE}$ and $\mathrm{TiO}_{2} \mathrm{NPS} / \mathrm{CPE}$, respectively. As can be seen on the surface of $\mathrm{CPE}$, the layer of irregular flakes of graphite powder was present and isolated from each other. After addition of $\mathrm{TiO}_{2} \mathrm{NPs}$ to the carbon paste, it can be seen that the spherical form of $\mathrm{TiO}_{2} \mathrm{NPs}$ with ca. 20-30 nm diameter was completely distributed on the surface of the modified electrode, indicating that the $\mathrm{TiO}_{2} \mathrm{NPs}$ was successfully incorporated into the CPE (see Figure 1b).

Figure 2 shows the energy dispersive $\mathrm{X}$-ray spectroscopy (EDS) and elemental analysis of $\mathrm{TiO}_{2} \mathrm{NPs} / \mathrm{CPE}$ electrode surface. Observation of intensive peaks related to the electron transmissions of titanium, oxygen and carbon
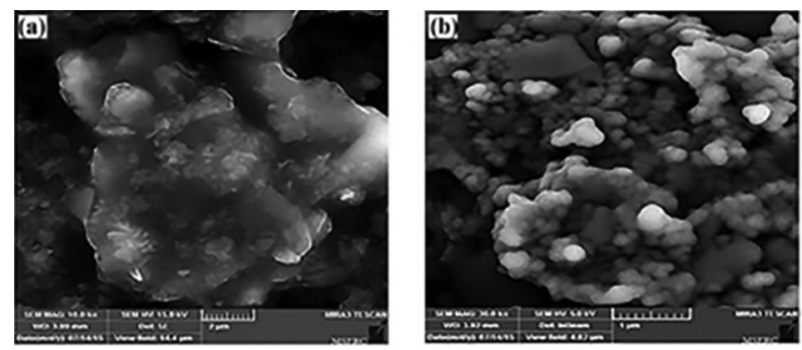

Figure 1. Representation of field emission scanning electron micrographs of (a) CPE and (b) $\mathrm{TiO}_{2} \mathrm{NPs} / \mathrm{CPE}$.

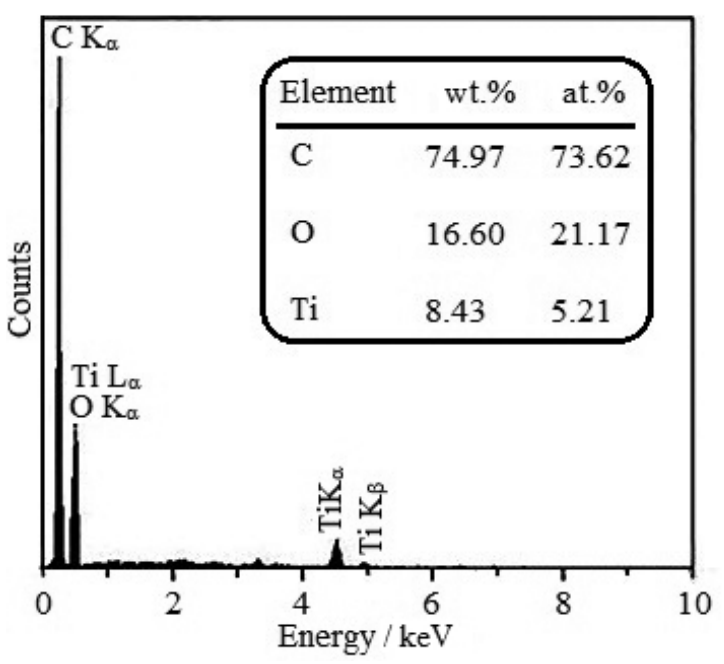

Figure 2. EDS spectrum of $\mathrm{TiO}_{2} \mathrm{NPs} / \mathrm{CPE}$ surface.

demonstrates the presence of $\mathrm{TiO}_{2} \mathrm{NPs}$ on the surface and between layers of graphite.

\section{Electrochemistry of fabricated electrodes}

Potassium ferricyanide $\left(\mathrm{K}_{4} \mathrm{Fe}(\mathrm{CN})_{6}\right)$ was selected as a probe to evaluate the performance of the fabricated bare $\mathrm{CPE}$ and $\mathrm{TiO}_{2} \mathrm{NPs} / \mathrm{CPE}$ electrodes using cyclic voltammetry (CV) technique. Figure 3 a illustrates the typical CVs of the electrochemical oxidation of $\mathrm{K}_{4} \mathrm{Fe}(\mathrm{CN})_{6}$ at the surface of the bare $\mathrm{CPE}$ and $\mathrm{TiO}_{2} \mathrm{NPs} / \mathrm{CPE}$ electrodes in the $10 \mathrm{mmol} \mathrm{L}^{-1}$ of $\mathrm{K}_{4} \mathrm{Fe}(\mathrm{CN})_{6}$ and $0.1 \mathrm{~mol} \mathrm{~L}^{-1}$ of $\mathrm{KCl}$ solution. It is obvious that the electron transfer rate was sluggish, with a peak-to-peak separation $\left(\Delta \mathrm{E}_{\mathrm{p}}\right)$ of $190 \mathrm{mV}$ at the CPE.

On the contrary, the $\mathrm{TiO}_{2} \mathrm{NPs} / \mathrm{CPE}$ displayed a well-shaped cyclic response for the $\mathrm{Fe}(\mathrm{CN})_{6}{ }^{3} / \mathrm{Fe}(\mathrm{CN})_{6}{ }^{4-}$ redox couple with a $\Delta \mathrm{E}_{\mathrm{p}}$ of $110 \mathrm{mV}$, indicating a dramatic increase in the electron transfer rate due to the high conductivity of $\mathrm{TiO}_{2}$ nanoparticles. This is a quasi-reversible system because $\Delta \mathrm{E}_{\mathrm{p}}$ is greater than $59 \mathrm{mV}$ that is expected for a reversible system. Therefore, the $\mathrm{TiO}_{2}$ nanoparticles in CPE could facilitate the electron transfer rate between the electron surface and electroactive 

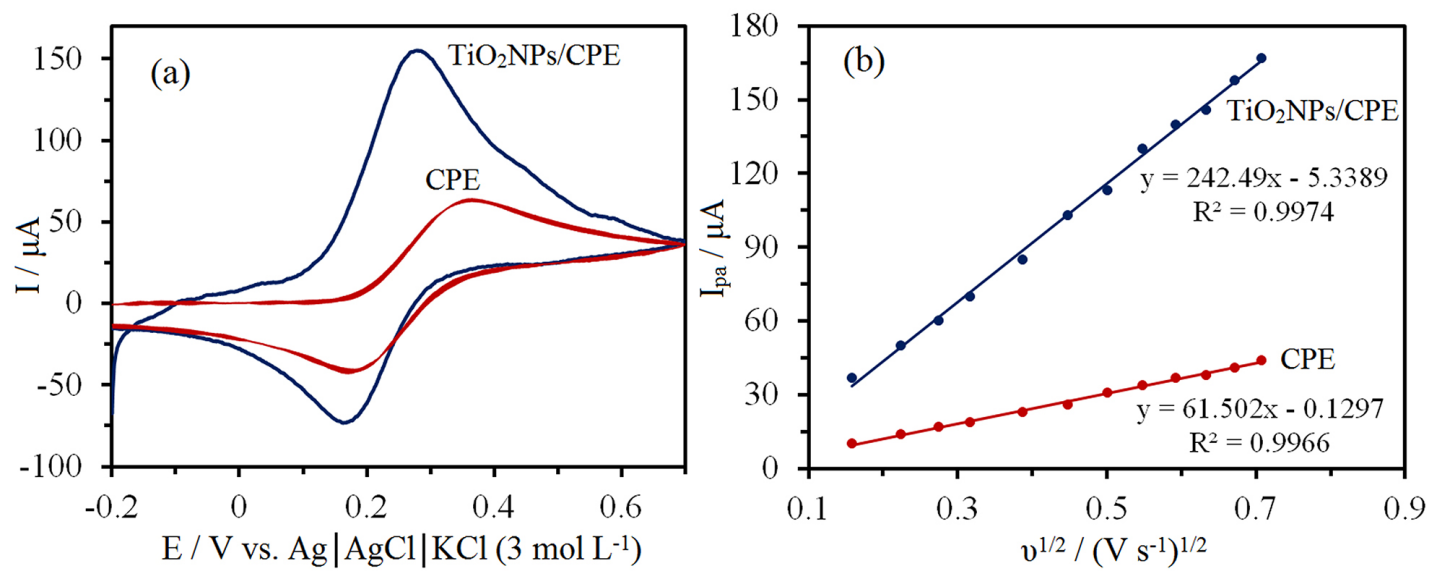

Figure 3. (a) The CVs of bare $\mathrm{CPE}$ and $\mathrm{TiO}_{2} \mathrm{NPs} / \mathrm{CPE}$ in the presence of $10 \mathrm{mmol} \mathrm{L}^{-1} \mathrm{~K}_{4} \mathrm{Fe}(\mathrm{CN})_{6}$ solution at a scan rate of $20 \mathrm{mV} \mathrm{s}^{-1}$ and $\mathrm{pH}$ of 7.0 in $0.1 \mathrm{~mol} \mathrm{~L}^{-1} \mathrm{KCl}$ as supporting electrolyte; (b) plot of $\mathrm{I}_{\mathrm{pa}}$ versus $\mathrm{v}^{1 / 2}$ at the surface of bare CPE and $\mathrm{TiO}_{2} \mathrm{NPs} / \mathrm{CPE}$ at various scan rates of 10, 25, 50, 75, $100,150,200,250,300,350,400,450$ and $500 \mathrm{mV} \mathrm{s}^{-1}$ for the oxidation of $1 \mathrm{mmol} \mathrm{L}^{-1} \mathrm{~K}_{4} \mathrm{Fe}(\mathrm{CN})_{6}$ in $0.1 \mathrm{~mol} \mathrm{~L}^{-1} \mathrm{KCl}$.

species. It is proposed that $\mathrm{TiO}_{2}$ nanoparticles present in the carbon paste electrode not only acted as a binder to fill in the blanks of the carbon paste, but also formed a layer of titanium dioxide nanoparticles on the electrode surface. This effect was previously reported for determination of carbamazepine in the pharmaceutical samples onto $\mathrm{Ag} / \mathrm{TiO}_{2}$ nanocomposite modified carbon paste electrode. ${ }^{24}$ The obtained result from $\mathrm{CV}$ of $\mathrm{TiO}_{2} \mathrm{NPs} / \mathrm{CPE}$ in various buffered solutions with different $\mathrm{pH}$ values does not show any shift in the anodic peak potentials for oxidation of $\mathrm{K}_{4} \mathrm{Fe}(\mathrm{CN})_{6}$ (data not shown). It can be concluded that the electrochemical behavior of the $\mathrm{Fe}(\mathrm{CN})_{6}{ }^{3-} / \mathrm{Fe}(\mathrm{CN})_{6}{ }^{4-}$ redox couple in the $\mathrm{TiO}_{2} \mathrm{NPs} / \mathrm{CPE}$ electrode is not dependent on the $\mathrm{pH}$ of solution.

The active surface areas of the fabricated electrodes were calculated by the $\mathrm{CV}$ method at various scan rates using $\mathrm{K}_{4} \mathrm{Fe}(\mathrm{CN})_{6}$ as a probe. For this approach, the Randles-Sevcik formula can be used:

$I_{p a}=0.4463 \mathrm{AC}_{0}\left(\frac{F^{3}}{R T}\right)^{1 / 2} n^{3 / 2} D^{1 / 2} U^{1 / 2}$

where $\mathrm{I}_{\mathrm{pa}}(\mathrm{A})$ refers to the anodic peak current, $\mathrm{A}\left(\mathrm{cm}^{2}\right)$ is the active surface area of the electrode, $\mathrm{C}_{0}\left(\mathrm{~mol} \mathrm{~cm}^{-3}\right)$ is the concentration of $\mathrm{K}_{4} \mathrm{Fe}(\mathrm{CN})_{6}, \mathrm{~F}$ is the Faraday's constant $\left(96485 \mathrm{C} \mathrm{mol}^{-1}\right), \mathrm{R}$ is the universal gas constant $\left(8.314 \mathrm{~J} \mathrm{~mol}^{-1} \mathrm{~K}^{-1}\right), \mathrm{T}$ is the absolute temperature $(298 \mathrm{~K}), \mathrm{n}$ is the electron transfer number, $\mathrm{D}\left(\mathrm{cm}^{2} \mathrm{~s}^{-1}\right)$ is the diffusion coefficient and $v\left(\mathrm{~V} \mathrm{~s}^{-1}\right)$ is the scan rate. For $1.0 \mathrm{mmol} \mathrm{L}^{-1} \mathrm{~K}_{4} \mathrm{Fe}(\mathrm{CN})_{6}$ in $0.1 \mathrm{~mol} \mathrm{~L}^{-1} \mathrm{KCl}$ as supporting electrolyte, the amount of $\mathrm{n}$ and $\mathrm{D}$ is 1 and $7.6 \times 10^{-6} \mathrm{~cm}^{2} \mathrm{~s}^{-1}$, respectively. ${ }^{25,26}$ Figure $3 \mathrm{~b}$ illustrates the plot of $\mathrm{I}_{\mathrm{pa}}$ versus $v^{1 / 2}$ for the oxidation of $\mathrm{K}_{4} \mathrm{Fe}(\mathrm{CN})_{6}$ on the surface of bare $\mathrm{CPE}$ and $\mathrm{TiO}_{2} \mathrm{NPs} / \mathrm{CPE}$ at various scan rates. Linear relationship between the anodic or cathodic peak currents and $v^{1 / 2}$ indicates a diffusion control process at the surfaces of both electrodes. In this experiment, the slopes $\mathrm{I}_{\mathrm{pa}}$ versus $\mathrm{v}^{1 / 2}$ were 61.50 and $242.49 \mu \mathrm{A}\left(\mathrm{V}^{-1} \mathrm{~s}^{-1}\right)^{1 / 2}$ for bare $\mathrm{CPE}$ and $\mathrm{TiO}_{2} \mathrm{NPs} / \mathrm{CPE}$, respectively. Therefore, the active microscopic surface areas were found to be 0.084 and $0.390 \mathrm{~cm}^{2}$ for the bare $\mathrm{CPE}$ and $\mathrm{TiO}_{2} \mathrm{NPs} / \mathrm{CPE}$, respectively. These results indicated that modification of $\mathrm{CPE}$ with the $\mathrm{TiO}_{2}$ nanoparticles causes an increase in the active surface area of the modified electrode.

Electrochemical behavior of $\mathrm{PRX}$ at $\mathrm{TiO}_{2} \mathrm{NPs} / \mathrm{CPE}$ and bare CPE

Inset in Figure 4 shows cyclic voltammograms of bare $\mathrm{CPE}$ and $\mathrm{TiO}_{2} \mathrm{NPs} / \mathrm{CPE}$ in the absence of PRX in the phosphate solution of $\mathrm{pH} 5.0$ at the potential range from 0.0 to $1.4 \mathrm{~V} v s$. $\mathrm{Ag}|\mathrm{AgCl}| \mathrm{KCl}\left(3 \mathrm{~mol} \mathrm{~L}^{-1}\right)$ and potential sweep rate of $25 \mathrm{mV} \mathrm{s}^{-1}$. As can be seen, no current can be obtained with these electrodes. Figure 4 displays the cyclic voltammograms of $0.3 \mathrm{mmol} \mathrm{L}^{-1} \mathrm{PRX}$ at bare CPE and $\mathrm{TiO}_{2} \mathrm{NPs} / \mathrm{CPE}$ in the phosphate solution of $\mathrm{pH} 5.0$ at the potential range from 0.0 to $1.4 \mathrm{~V} v s$. $\mathrm{Ag}|\mathrm{AgCl}| \mathrm{KCl}$ $\left(3 \mathrm{~mol} \mathrm{~L}^{-1}\right)$ and potential sweep rate of $25 \mathrm{mV} \mathrm{s}^{-1}$. The PRX exhibited a well-defined irreversible anodic peak at both $\mathrm{TiO}_{2} \mathrm{NPs} / \mathrm{CPE}$ and bare CPE. The anodic voltammetric signals can be ascribed to the oxidation of $-\mathrm{NH}$ group. ${ }^{27}$ The electroanalytical performance of $\mathrm{TiO}_{2} \mathrm{NPs} / \mathrm{CPE}$ was advantageous over that observed at the bare CPE. The cyclic voltammograms of PRX showed about 2.5 times enhancement in the oxidation peak current at $\mathrm{TiO}_{2} \mathrm{NPs} / \mathrm{CPE}(165 \mu \mathrm{A})$ as compared to a bare CPE $(65 \mu \mathrm{A})$. The higher electrocatalytic behavior of the modified electrode corresponds to the presence of a larger number of electrochemical active sites and decrease in the charge transfer resistance in the $\mathrm{TiO}_{2} \mathrm{NPs} / \mathrm{CPE}$ rather 
than in the bare CPE. These results indicated that the electrochemical oxidation of PRX has higher electron transfer kinetics in the surface of modified electrode, therefore, somewhat improving the sensitivity for voltammetric measurement.

\section{Effect of $\mathrm{pH}$}

The influence of $\mathrm{pH}$ on the electrooxidation of $0.3 \mathrm{mmol} \mathrm{L}^{-1} \mathrm{PRX}$ at $\mathrm{TiO}_{2} \mathrm{NPs} / \mathrm{CPE}$ was investigated in the $\mathrm{pH}$ range of 2.0-13.0 (see Figure 5a). Optimum peak current was achieved at $\mathrm{pH} 5$, therefore, a phosphate solution of $\mathrm{pH} 5.0$ was used for subsequent work. It is seen that increasing the $\mathrm{pH}$, the peak current decreases due to $\mathrm{pH}$ dependence of half wave potential, which indicates the involvement of protons in the electrode process and finally dislocated in alkaline $\mathrm{pH}$ due to a lower number of available protons. ${ }^{27}$ It can be seen from Figure $5 \mathrm{~b}$ that with increase in $\mathrm{pH}$ of the solution, the oxidation current was observed to be shifted towards lower potentials.

The linear dependence of peak potential on the $\mathrm{pH}$ in the range of 2.0-13.0 can be expressed by the following equation: $\mathrm{E}_{\mathrm{p}}(\mathrm{V})=-0.0645 \mathrm{pH}+1.1706$. A slope value of $0.0645 \mathrm{~V} / \mathrm{pH}$ is close to the expected slope of $0.059 \mathrm{~V} / \mathrm{pH}$, which indicates that the number of electrons and protons participating in the oxidation of PRX is the same. ${ }^{28}$

\section{Effect of potential sweep rate}

Useful information with regard to electrochemical mechanisms can be obtained from the relationship between the peak current and the sweep rate. Therefore, the cyclic voltammetric investigations of PRX $\left(0.3 \mathrm{mmol} \mathrm{L}^{-1}\right)$ were performed on the surface of $\mathrm{TiO}_{2} \mathrm{NPs} / \mathrm{CPE}$ at different sweep rates in the phosphate solution of $\mathrm{pH}$ 5.0. The $\mathrm{PRX}$ at the surface of $\mathrm{TiO}_{2} \mathrm{NPs} / \mathrm{CPE}$ exhibits a single well defined oxidation peak at $0.9 \mathrm{~V}$ vs. $\mathrm{Ag}|\mathrm{AgCl}| \mathrm{KCl}$ ( $3 \mathrm{~mol} \mathrm{~L}^{-1}$ ). Since no anodic peak was observed in the reverse scan, therefore, the nature of the electrode process is irreversible. Figure 6a illustrates the influence of the sweep rate on the oxidation current of PRX in the range of $20-450 \mathrm{mV} \mathrm{s}^{-1}$. From Figure $6 \mathrm{~b}$, it can be seen that there is no linear relationship between peak current and scan rate; meanwhile, a linear relationship

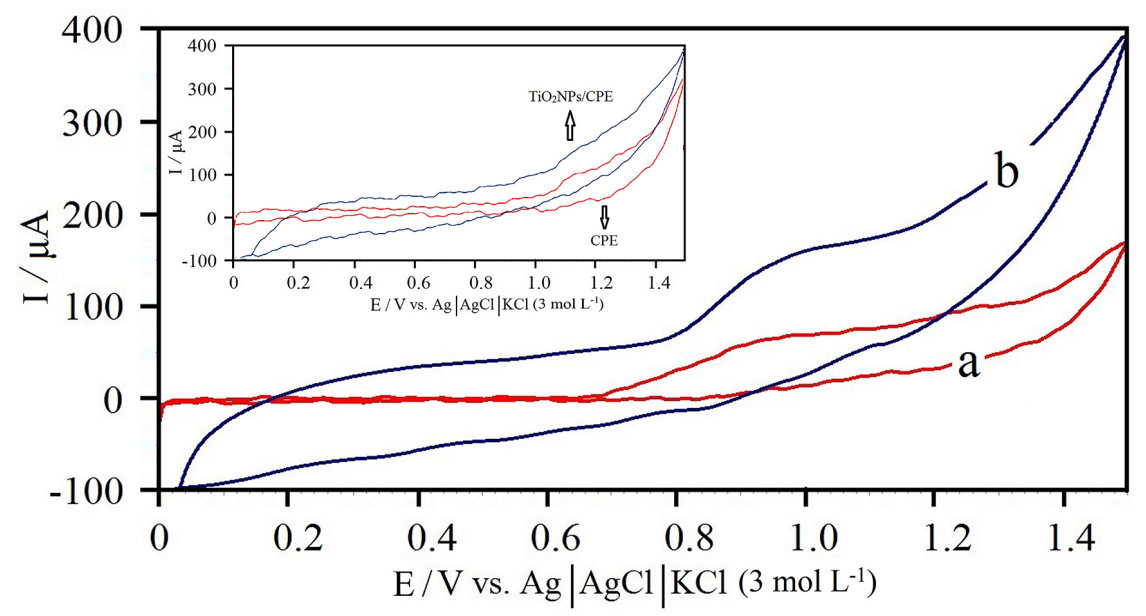

Figure 4. The cyclic voltammograms of $0.3 \mathrm{mmol} \mathrm{L}^{-1} \mathrm{PRX}$ at the surface of (a) bare $\mathrm{CPE}$ and (b) $\mathrm{TiO}_{2} \mathrm{NPs} / \mathrm{CPE}$ in the phosphate solution of $\mathrm{pH} 5.0$ and scan rate of $25 \mathrm{mV} \mathrm{s}^{-1}$. Inset shows $\mathrm{CVs}$ of modified electrodes in the phosphate solution of $\mathrm{pH}$ 5.0.
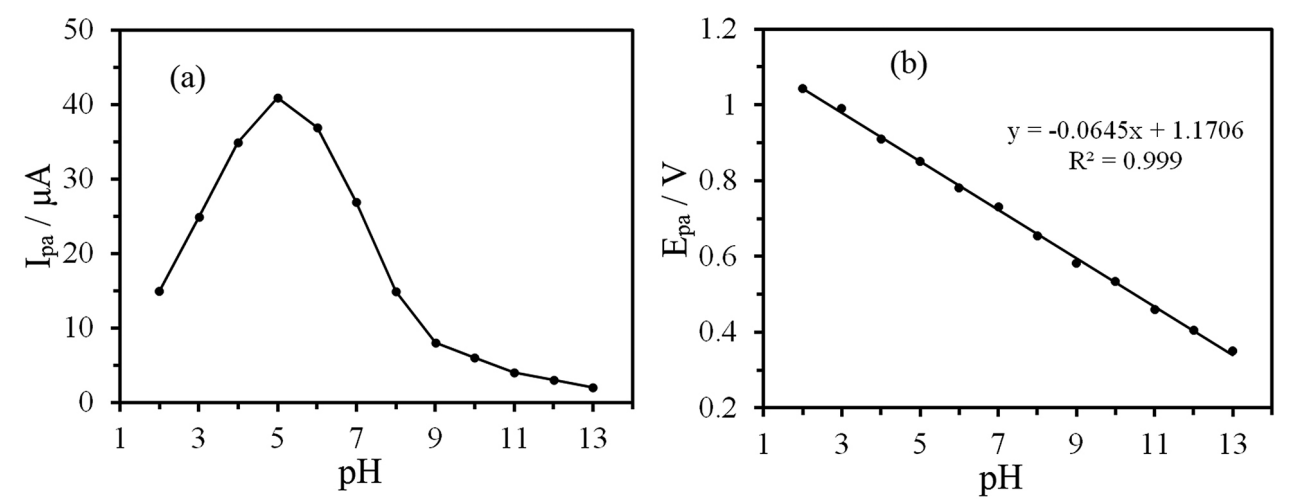

Figure 5. The effect of $\mathrm{pH}$ on the (a) peak current and (b) peak potential of $0.3 \mathrm{~mol} \mathrm{~L}^{-1} \mathrm{PRX}$ at $\mathrm{TiO}_{2} \mathrm{NPs} / \mathrm{CPE}$ and scan rate of $25 \mathrm{mV} \mathrm{s}^{-1}$. 
between anodic peak current $\left(\mathrm{I}_{\mathrm{pa}}\right)$ vs. square root of scan rate $\left(v^{1 / 2}\right)$ was obtained (see Figure $6 c$ ), suggesting the diffusion of PRX at the surface of $\mathrm{TiO}_{2} \mathrm{NPs} / \mathrm{CPE}$, which can be expressed by the following expression: ${ }^{29,30}$ $\mathrm{I}_{\mathrm{pa}}(\mu \mathrm{A})=12.492 \mathrm{v}^{1 / 2}\left(\mathrm{mV} \mathrm{s}^{-1}\right)+91.051, \mathrm{R}^{2}=0.998$.

From theoretical point, a slope of 0.5 or 1.0 is expected for the plot of $\log \mathrm{I}_{\mathrm{pa}} v s . \log v$ under diffusion or adsorption control, respectively. ${ }^{31}$ A linear dependence is observed between $\log \mathrm{I}_{\mathrm{pa}}$ and $\log v$ at the surface of $\mathrm{TiO}_{2} \mathrm{NPs} / \mathrm{CPE}$ in the PRX oxidation (see Figure 6d). From linear section, the slope of 0.2922 is found that is near to the theoretically predicted value of 0.5 for a purely diffusion-controlled current. However, the contribution of a kinetic limitation to the overall process causes a small alteration in the theoretical value..$^{31,32}$

The electrochemical kinetic parameters, the number of electrons transferred $(n)$, electron transfer coefficient $(\alpha)$
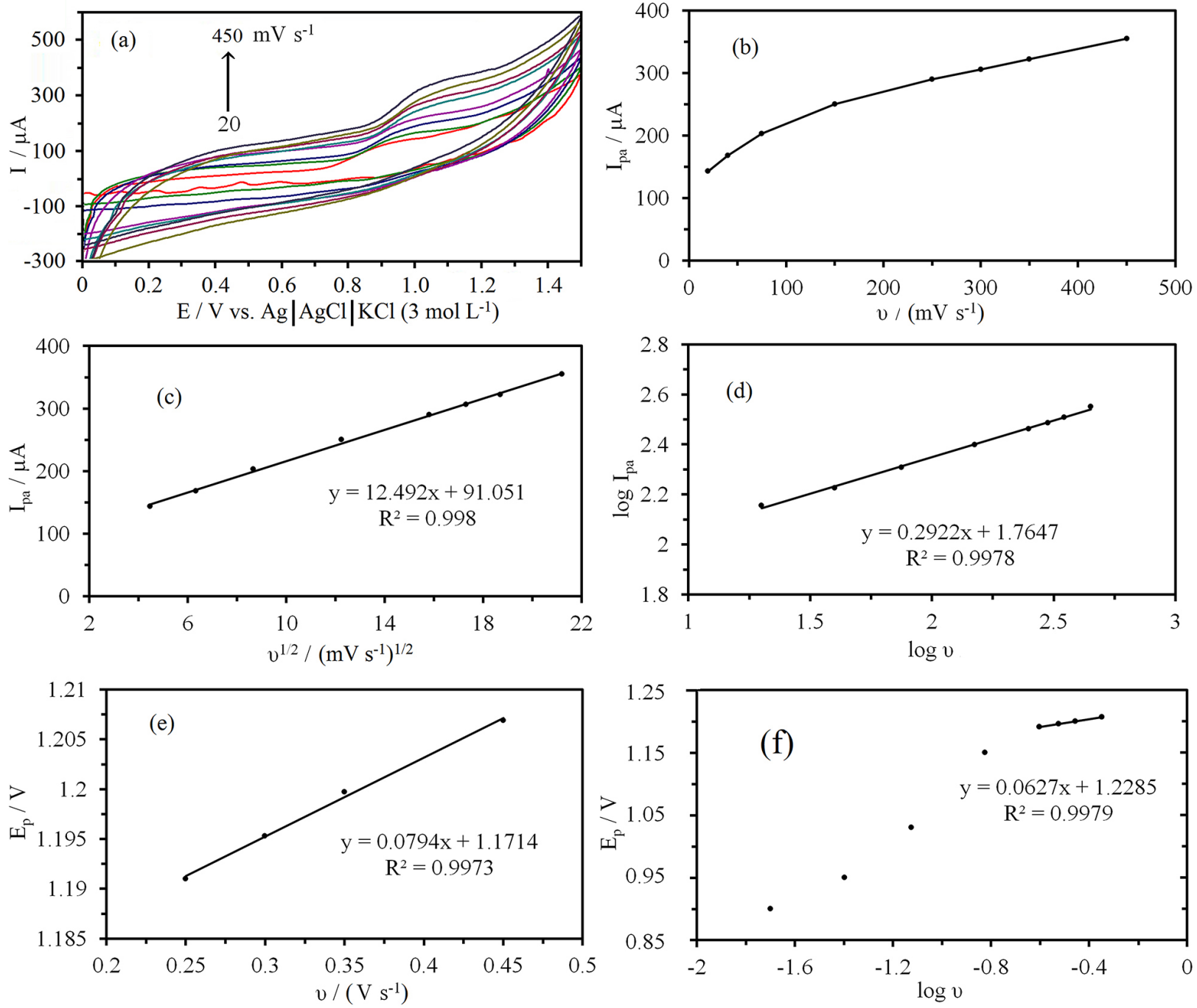

Figure 6. (a) The CVs of $5 \mathrm{mmol} \mathrm{L}^{-1} \mathrm{PRX}$ at the $\mathrm{TiO}_{2} \mathrm{NPs} / \mathrm{CPE}$ in the phosphate solution (pH 5.0) at various scan rates from inner to outer: 20 , 40, 75 , $150,250,300,350$ and $450 \mathrm{mV} \mathrm{s}^{-1}$; (b) plot of $\mathrm{I}_{\mathrm{pa}}$ and $v$; (c) plot of $\mathrm{I}_{\mathrm{pa}}$ and $v^{1 / 2}$; (d) plot of $\log \mathrm{I}_{\mathrm{pa}} v s$. $\log v$; (e) plot of $\mathrm{E}_{\mathrm{pa}} v s$. $v$ and (f) plot of $\mathrm{E}_{\mathrm{pa}} v s$. $\log v$ for CVs showed in the (a). 
$2.025 \mathrm{~s}^{-1}$, respectively. Since, for a totally irreversible electron transfer reaction, $\alpha$ was assumed to be 0.5 , the value of $\mathrm{n}$ was calculated to be 1.886 . This indicated that two electrons have taken part in the irreversible oxidation step. ${ }^{35}$ Also, the large value of electron transfer rate constant indicates the strong ability of the $\mathrm{TiO}_{2} \mathrm{NPs} / \mathrm{CPE}$ to promote electron transfer between PRX and the electrode surface.

\section{Electrooxidation mechanism of PRX}

Based on information obtained from cyclic voltammetry, the effect of $\mathrm{pH}$ and scan rate and also other studies made previously on voltammetric determination of PRX and electrochemical oxidation of amines, ${ }^{36-39}$ the electrooxidation process of PRX at the modified electrode surface is proposed as the reaction shown in Scheme 2.

\section{Chronoamperometric studies}

Chronoamperometric measurements of PRX at the surface of $\mathrm{TiO}_{2} \mathrm{NPs} / \mathrm{CPE}$ were carried out by setting the working electrode potential at $0.9 \mathrm{~V} v s . \mathrm{Ag}|\mathrm{AgCl}| \mathrm{KCl}$ ( $3 \mathrm{~mol} \mathrm{~L}^{-1}$ ) for various concentrations of PRX in the phosphate solution ( $\mathrm{pH}$ 5.0), as presented in Figure 7A. For an electroactive material (i.e., PRX in this case) with a diffusion coefficient, D, the current observed for the electrochemical reaction under mass transport-limited conditions can be described by the Cottrell equation: ${ }^{40,41}$

$\mathrm{I}=\mathrm{nFACD}^{1 / 2} \pi^{-1 / 2} \mathrm{t}^{-1 / 2}$

where $\mathrm{n}$ is the number of electron (i.e., 2), $\mathrm{F}$ is the Faraday number $\left(96485 \mathrm{C} \mathrm{mol}^{-1}\right)$, A is the area of the electrode $\left(0.0962 \mathrm{~cm}^{2}\right), \mathrm{C}$ is the known concentration of PRX and $D$ is the diffusion coefficient. Experimental plots of I vs. $t^{-1 / 2}$ were drawn and the best fits for different concentrations of PRX were determined (Figure 7B). The slopes of the resulting straight lines were then plotted vs. PRX concentration (Figure 7C). From the resulting slope and Cottrell equation, the mean value of $\mathrm{D}$ was found to be $3.92 \times 10^{-7} \mathrm{~cm}^{2} \mathrm{~s}^{-1}$.

Chronoamperometry can also be used to evaluate the catalytic rate constant, $\mathrm{k}_{\mathrm{cat}}$, for the reaction between PRX and $\mathrm{TiO}_{2} \mathrm{NPs} / \mathrm{CPE}$ according to the method of Galus:42

$\mathrm{I}_{\mathrm{C}} / \mathrm{I}_{\mathrm{L}}=\gamma^{1 / 2}\left[\pi^{1 / 2} \operatorname{erf}\left(\gamma^{1 / 2}\right)+\exp (-\gamma) / \gamma^{1 / 2}\right]$

where $\mathrm{I}_{\mathrm{C}}$ is the catalytic current of $\mathrm{PRX}$ at $\mathrm{TiO}_{2} \mathrm{NPs} / \mathrm{CPE}$, $I_{L}$ is the limited current in the absence of PRX, and $\gamma=\mathrm{k}_{\mathrm{cat}} \mathrm{C}_{\mathrm{b}} \mathrm{t}$ is the argument of the error function $\left(\mathrm{C}_{\mathrm{b}}\right.$ is the bulk concentration of PRX). When $\gamma$ exceeds 2 , the error function is almost equal to 1 , so equation 4 can be reduced to:

$\mathrm{I}_{\mathrm{C}} / \mathrm{I}_{\mathrm{L}}=\pi^{1 / 2} \gamma^{1 / 2}=\pi^{1 / 2}\left(\mathrm{k}_{\mathrm{cat}} \mathrm{C}_{\mathrm{b}} \mathrm{t}\right)^{1 / 2}$

where $t$ is the elapsed time. Equation 5 can be used to estimate $\mathrm{k}_{\text {cat }}$ for the catalytic process from the slope of $I_{C} / I_{L} v s . t^{1 / 2}$ at a given PRX concentration (Figure 7D). The average value of $\mathrm{k}_{\text {cat }}$ was calculated to be $12.64 \mathrm{~cm}^{3} \mathrm{~mol}^{-1} \mathrm{~s}^{-1}$.

\section{Analytical applications}

\section{Calibration curve}

In order to develop an electroanalytical method for the PRX determination, we have selected the DPV method. The phosphate solution of $\mathrm{pH} 5.0$ was selected as the supporting electrolyte for the quantification of PRX as it gave maximum peak current. The DPV measurement conditions were optimized by monitoring the variation in peak current with pulse amplitude, pulse width and sweep rate. The quantitative determination of PRX was based on the dependence of oxidation peak current on the PRX

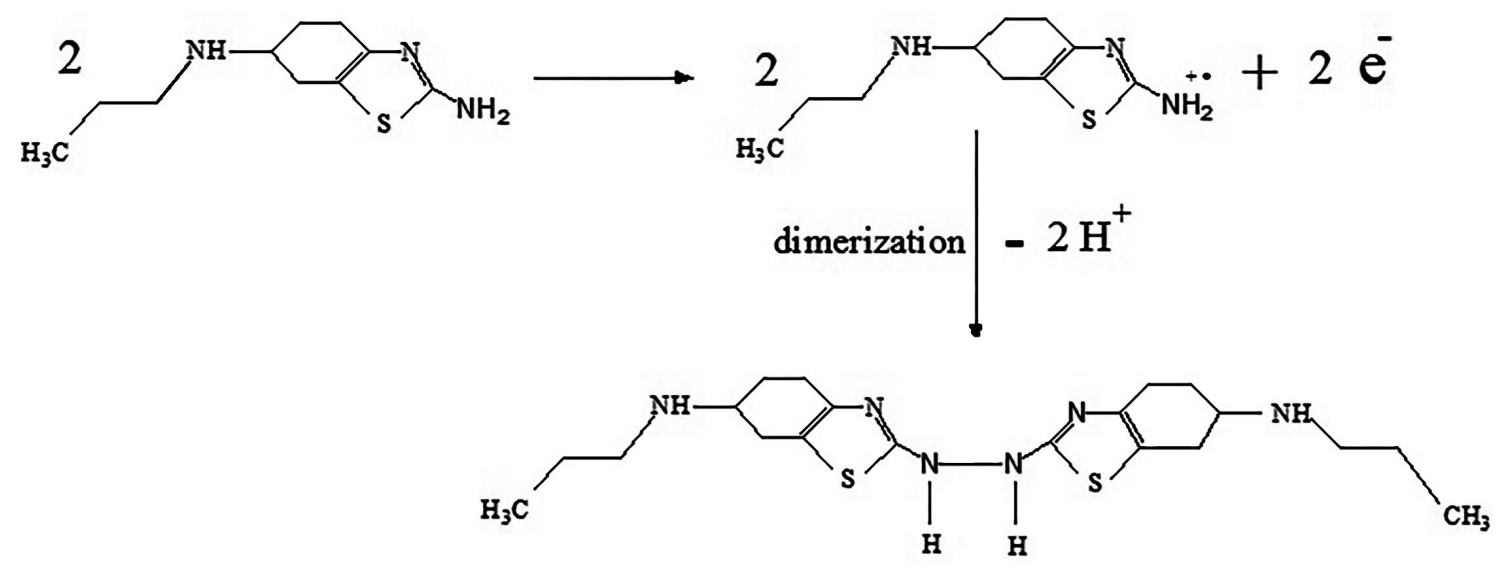



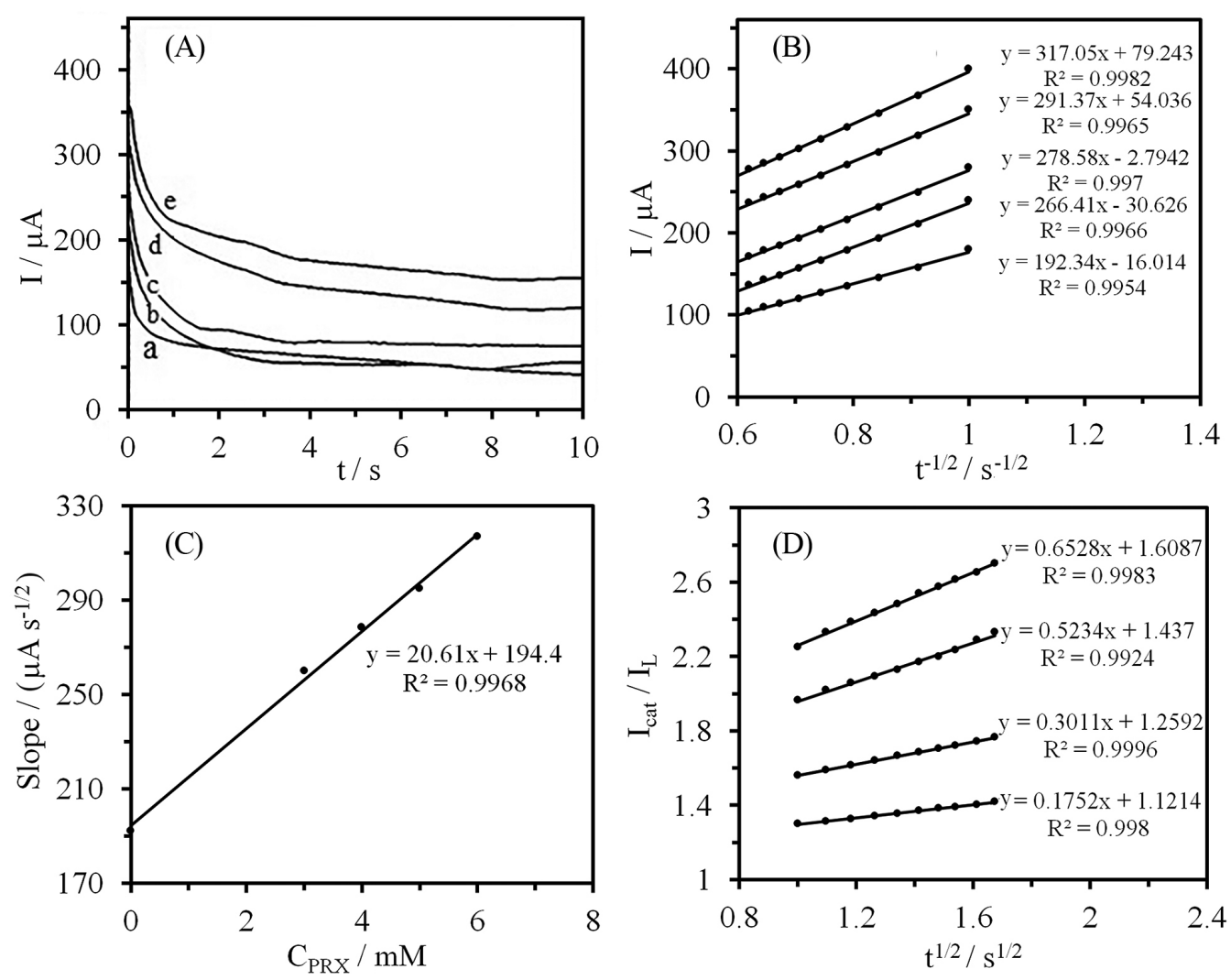

Figure 7. (A) Chronoamperograms obtained at $\mathrm{TiO}_{2} \mathrm{NPs} / \mathrm{CPE}$ in the phosphate solution ( $\mathrm{pH} 5.0$ ) for PRX concentrations of (a) 0.0 ; (b) 0.3; (c) 0.4; (d) 0.5 and (e) $0.6 \mathrm{mmol} \mathrm{L}^{-1}$; (B) plots of I vs. $\mathrm{t}^{-1 / 2}$ obtained from chronoamperograms (a)-(e) in (A); (C) plot of the slope of the straight lines against PRX concentration; (D) dependence of $\mathrm{I}_{\text {cat }} / \mathrm{I}_{1}$ on $\mathrm{t}^{1 / 2}$ derived from the data in chronoamperogram (a)-(e) in (A).

concentration. The differential pulse voltammograms of PRX at different concentrations is shown in Figure 8a. Under the optimized conditions (sweep rate: $25 \mathrm{mV} \mathrm{s}^{-1}$, pulse amplitude: $50 \mathrm{mV}$, pulse width: $50 \mathrm{~ms}$ ), a linear relation between the peak current and PRX concentration was observed in the range of $0.46-100 \mu \mathrm{M}$. Deviation from the linearity was observed above this concentration level perhaps due to the adsorption of oxidation product of

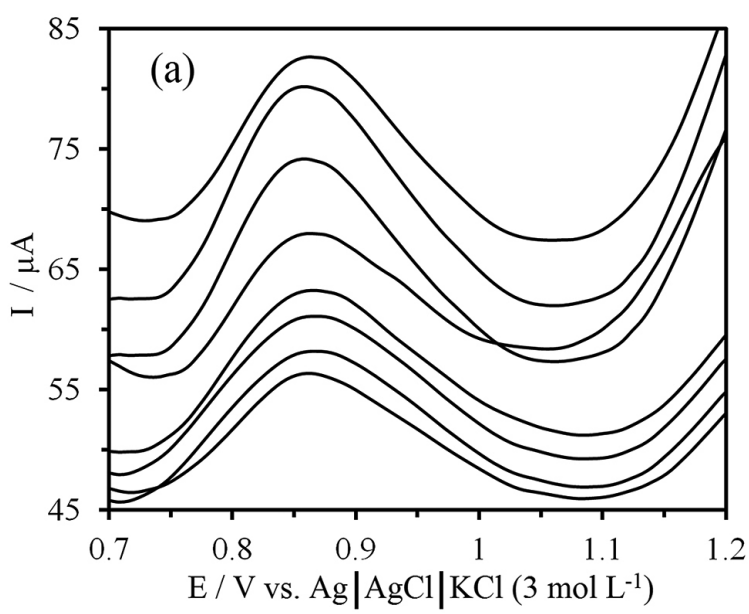

PRX on the surface of $\mathrm{TiO}_{2} \mathrm{NPs} / \mathrm{CPE}$. The dependence of oxidation peak current $v s$. the concentration of $\mathrm{PRX}$ at the surface of $\mathrm{TiO}_{2} \mathrm{NPs} / \mathrm{CPE}$ is shown in Figure 8b. The value of $F$ for regression obtained was 989.2. The $F$ value is used to test the null hypothesis that the total variance in y (i.e., oxidation peak current) is equal to the variance due to error. A value of $F$ greater than the value from the tables at the chosen confidence level indicates that the null hypothesis

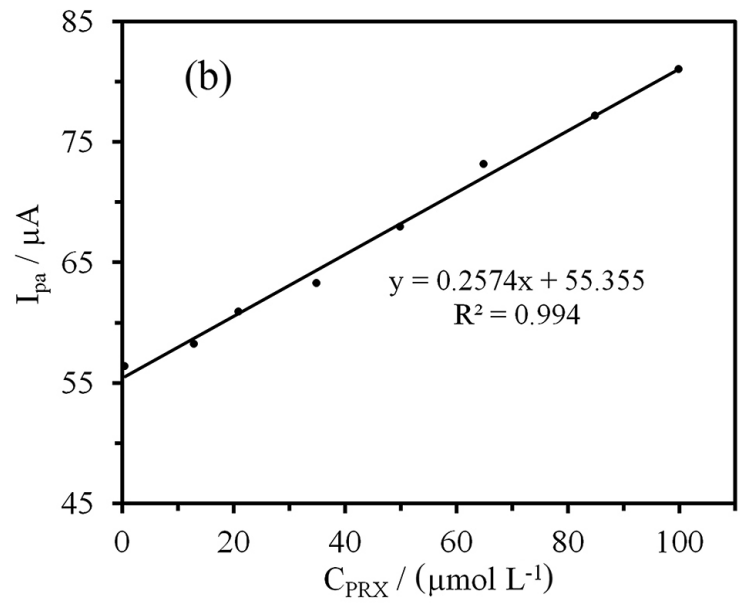

Figure 8. (a) DPVs of $\mathrm{PRX}$ at $\mathrm{TiO}_{2} \mathrm{NPs} / \mathrm{CPE}$ in the phosphate solution of $\mathrm{pH} 5.0$ at different concentrations from inner to outer: $0.6,13,21,35,50,65$, 85 and $100 \mu \mathrm{mol} \mathrm{L}^{-1}$; (b) calibration plot of PRX. 
should be rejected and that the regression is significant. This result is in agreement with the obtained $\mathrm{R}^{2}$ of regression model (i.e., $\mathrm{R}^{2}=0.994$ ).

The limit of detection (LOD) and limit of quantification (LOQ) were estimated by the following equations: ${ }^{27}$

LOD $=3$ S.D. $/ \mathrm{m}$

$\mathrm{LOQ}=10$ S.D. $/ \mathrm{m}$

where S.D. is the standard deviation of the intercept and $\mathrm{m}$ is the slope of the calibration curve. The LOD and LOQ were calculated to be 0.14 and $0.46 \mu \mathrm{mol} \mathrm{L}^{-1}$, respectively. The calibration curve was linear in the concentration lower than $100 \mu \mathrm{mol} \mathrm{L} \mathrm{L}^{-1}$. Then, linear dynamic range (LDR) obtained was 0.46-100 $\mu \mathrm{mol} \mathrm{L}^{-1}$.

\section{Effect of interferences}

The effects of some biological interferences have been investigated on the electrochemical oxidation of PRX. This was performed by recording the DPVs of $10 \mu \mathrm{M}$ PRX at $\mathrm{TiO}_{2} \mathrm{NPs} / \mathrm{CPE}$ for 5 times with varying amounts of each of the interfering substance $\left(5-100 \mu \mathrm{mol} \mathrm{L}^{-1}\right)$. For each voltammetric measurement (in the absence and presence of interferences), freshly modified electrode was used to obtain the reproducible results. The corresponding results are given in Table 1. The experimental results show that modified electrode yield a small change response for the interfering agents. It confirms that $\mathrm{TiO}_{2} \mathrm{NPs} / \mathrm{CPE}$ can be considered as a good electrochemical sensor for recognition of PRX.
Determination of PRX in the pharmaceutical tablets and spiked plasma samples

The $\mathrm{TiO}_{2} \mathrm{NPs} / \mathrm{CPE}$ was directly used to determine the content of PRX in 0.35 and $0.7 \mathrm{mg}$ tablets. Ten tablets were weighed and grounded to an homogeneous fine powder in a mortar. The powder was then transferred in $100 \mathrm{~mL}$ distilled water by ultrasonication. Then, different adequate amount of prepared solutions was diluted to $10 \mathrm{~mL}$ with the phosphate solution ( $\mathrm{pH} \mathrm{5.0)}$ and transferred to the voltammetric cell for the voltammetric determinations. The results listed in Table 2 agreed satisfactorily with the labeled content of PRX. Low values of the relative standard deviation (RSD, 2.24\%) indicated good reproducibility of the results.

The applicability of the proposed method was examined by analyzing PRX in plasma samples employing the $\mathrm{TiO}_{2} \mathrm{NPs} / \mathrm{CPE}$. Serum samples were spiked with known amounts of PRX and analyzed by recording DPVs. The amount of PRX in human serum samples was determined by referring to the calibration pot. The obtained results in Table 3 indicated good recovery of PRX.

Repeatability, stability and reproducibility of the modified electrode

The repeatability of the $\mathrm{TiO}_{2} \mathrm{NPs} / \mathrm{CPE}$ was investigated by repetitive recording at a fixed PRX concentration of $0.3 \mathrm{mM}$. The RSD for the peak currents in CVs based on five replicates was $2.7 \%$, indicating excellent repeatability of the modified electrode response. Also,

Table 1. The effects of interferences on the DPV response of $10 \mu \mathrm{M}$ PRX at $\mathrm{TiO}_{2} \mathrm{NPs} / \mathrm{CPE}$

\begin{tabular}{lccc}
\hline Interference & Concentration $\left./(\mu \mathrm{mol} \mathrm{L})^{-1}\right)$ & Current $/ \mu \mathrm{A}$ & Signal change / \% \\
\hline PRX (no interferent) & 10 & 60.83 & - \\
Dextromethorphan & 50 & 62.61 & 2.93 \\
Diphenylhydramine & 60 & 57.98 & 4.68 \\
Metronidazole & 70 & 64.38 & 5.83 \\
Phenobarbital & 100 & 62.96 & 3.50 \\
Phenylaniline & 100 & 58.51 & 3.81 \\
Phenytoin & 80 & 63.40 & 4.22 \\
Theophylline & 80 & 59.85 & 1.61 \\
Tryptophan & 90 & 59.23 & 2.63 \\
Tyrosine & 100 & 64.56 & 6.13 \\
\hline
\end{tabular}

Table 2. Determination results of PRX in the commercial tablets $(\mathrm{n}=5) ; \mathrm{t}_{\mathrm{tab}}(95 \%)=2.78$

\begin{tabular}{lcccccc}
\hline Tablet & Sample & $\begin{array}{c}\text { Labeled } \\
\text { claim } / \mathrm{mg}\end{array}$ & $\begin{array}{c}\text { Mean amount } \\
\text { found / mg }\end{array}$ & $\begin{array}{c}\text { Added / } \\
(\mu \mathrm{mol} \mathrm{L})\end{array}$ & $\begin{array}{c}\text { Found / } \\
(\mu \mathrm{mol} \mathrm{L})\end{array}$ \\
\hline PRX & 1 & 0.35 & $0.34 \pm 0.01$ & 3.01 & $2.94 \pm 0.19$ & 97.67 \\
PRX & 2 & 0.7 & $0.72 \pm 0.02$ & 6.02 & $6.16 \pm 0.31$ & 102.32 \\
\hline
\end{tabular}

RSD: Relative standard deviation. 
Table 3. Results for determination of PRX in spiked human serum samples $(n=5)$ by proposed sensor; $t_{\text {tab }}(95 \%)=2.78$

\begin{tabular}{lcccc}
\hline Sample & Added $/\left(\mu \mathrm{mol} \mathrm{L}^{-1}\right)$ & Found $\left./(\mu \mathrm{mol} \mathrm{L})^{-1}\right)$ & Recovery / $\%$ & RSD / \% \\
\hline Serum 1 & 15 & $14.90 \pm 0.81$ & 99.33 & 9.55 \\
Serum 2 & 0.80 & $0.76 \pm 0.02$ & 102.50 & 3.61 \\
Serum 3 & 55 & $56.38 \pm 3.22$ & 98.43 & 3.02 \\
Serum 4 & 30 & $29.53 \pm 1.80$ & 98.74 & 2.71 \\
Serum 5 & 90 & $88.86 \pm 3.87$ & 2.22 \\
\hline
\end{tabular}

RSD: Relative standard deviation.

using the $\mathrm{TiO}_{2} \mathrm{NPs} / \mathrm{CPE}$ daily and storing under ambient conditions over a period of 40 days, the electrode retained $97.3 \%$ of its initial peak current response for a PRX concentration of $0.3 \mathrm{mmol} \mathrm{L}^{-1}$, which shows long-term stability of the modified electrode. Also, the fabrication reproducibility was evaluated by preparing five modified electrodes independently. The RSD for peak current determinations with five prepared electrodes on $0.3 \mathrm{mmol}$ $\mathrm{L}^{-1} \mathrm{PRX}$ was calculated to be $3.4 \%$. The repeatability and stability of $\mathrm{TiO}_{2} \mathrm{NPs} / \mathrm{CPE}$ were also examined by DPV measurements of $20.0 \mu \mathrm{mol} \mathrm{L}{ }^{-1}$ PRX. The RSD for five successive assays was $1.8 \%$. When using five different $\mathrm{TiO}_{2} \mathrm{NPs} / \mathrm{CPE}$, the RSD\% for five measurements (for each one) was $2.8 \%$. When the electrode was stored in the laboratory, the modified electrode retains $97.5 \%$ of its initial response after a week and $95 \%$ after 30 days. The results indicate that the modified electrode has a good repeatability and reproducibility in both preparation procedure and voltammetric determinations with good long-term stability. So far, few studies have been reported for electrochemical determination of PRX. The results of this work were compared with other previous work ${ }^{27,28,34,36}$ and are shown in Table 4.

\section{Conclusions}

In the present study, electrochemical determination of pramipexole was studied using modified carbon paste electrode with $\mathrm{TiO}_{2}$ nanoparticles $\left(\mathrm{TiO}_{2} \mathrm{NPs} / \mathrm{CPE}\right)$ via $\mathrm{CV}$, DPV and chronoamperometry techniques. The developed methodology of this study was simple, fast, sensitive and cheap, especially in comparison with sophisticated techniques such as chromatography. The fabricated sensor identified PRX in the linear range of $0.46-100 \mu \mathrm{mol} \mathrm{L} \mathrm{L}^{-1}$ by DPV technique. The proposed electrochemical sensor was well selective for PRX in the presence of common interferences. Furthermore, it shows good reproducibility and repeatability. Besides, the modified electrode has been applied successfully for the determination of PRX in the pharmaceutical tablets and spiked plasma samples.

\section{Acknowledgments}

This work was supported by the Babol University of Technology (Islamic Republic of Iran). Also, we are very thankful to PhD Afshin Sarvari for the proposal of PRX electrooxidation mechanism.

Table 4. Comparison of the analytical performance of $\mathrm{TiO}_{2} \mathrm{NPs}$ modified carbon paste electrode (present work) with previously reported electrochemical methods

\begin{tabular}{|c|c|c|c|c|c|}
\hline Method & Electrode & $\mathrm{pH}$ & $\mathrm{LOD} /\left(\mu \mathrm{mol} \mathrm{L} \mathrm{L}^{-1}\right)$ & $\mathrm{LDR} /(\mu \mathrm{mol} \mathrm{L}-1)$ & Reference \\
\hline$\overline{\text { SWV }}$ & PANI- $\mathrm{Bi}_{2} \mathrm{O}_{3} / \mathrm{GCE}^{\mathrm{a}}$ & 4.5 & 0.0052 & $0.0118-0.0946$ & 27 \\
\hline SWV & $\mathrm{GRP} / \mathrm{GCE}^{\mathrm{b}}$ & - & $6.05 \times 10^{-5}$ & $1.9 \times 10^{-4}-1.4 \times 10^{-3}$ & 28 \\
\hline DPV & $\mathrm{ERGO} / \mathrm{GCE}^{\mathrm{c}}$ & 6 & 0.0028 & $0.01-15$ & 34 \\
\hline $\mathrm{CV}$ and amperometry & MWCNT/GCE & 7 & $\begin{array}{c}0.22 \text { (by CV) } \\
0.20 \text { (by amperometry) }\end{array}$ & $\begin{array}{c}12.5-313 \text { (by CV) } \\
5-340 \text { (by amperometry) }\end{array}$ & 36 \\
\hline $\mathrm{CE}$ & - & - & $4.7 \times 10^{-5}$ & $1.18 \times 10^{-4}-0.0047$ & 43 \\
\hline HPLC & - & - & - & $4.73 \times 10^{-5}-4.73 \times 10^{-2}$ & 44 \\
\hline Spectrophotometry & - & - & 0.0021 & $0.024-0.71$ & 45 \\
\hline DPV & $\mathrm{TiO}_{2} \mathrm{NPs} / \mathrm{CPE}$ & 5 & 0.14 & $0.46-100$ & this work \\
\hline
\end{tabular}

aPolyaniline-bismuth oxide nanocomposite modified glassy carbon electrode; ${ }^{b}$ graphene modified glassy carbon electrode; ${ }^{c}$ glassy carbon electrode modified with electrochemically reduced graphene oxide; ${ }^{d}$ multi-walled carbon nanotubes-modified glassy carbon electrode. SWV: squarewave voltammetry; DPV: differential pulse voltammetry; CE: capillary electrophoresis; HPLC: high-performance liquid chromatography; LOD: limit of detection; LDR: linear dynamic range. 


\section{References}

1. Leentjens, A. F. G.; Drugs 2011, 71, 273.

2. Lavudu. P.; Rani, A. P.; Sekaran, C. B.; Kumar, K. S.; Ramesh, A.; Chem. Sci. J. 2012, 3, 1.

3. Leentjens, F. G.; Koester, J.; Fruh, B.; Toby, D.; Shephard, S.; Barone, P.; Houben, J. G.; Clin. Ther. 2009, 31, 89.

4. Srinu, B. G.; Raju, C.; Asian J. Chem. 2007, 19, 816.

5. Lau, Y. Y.; Hanson, G. D.; Ichhpurani, N.; J. Chromatogr. B 1996, 683, 217.

6. Lau, Y. Y.; Selenka, J. M.; Hanson, G. D.; Talat, R.; Ichhpurani, N.; J. Chromatogr. B 1996, 683, 209.

7. Pathare, D. B.; Jadhav, A. S.; Shingare, M. S.; J. Pharm. Biomed. Anal. 2006, 41, 1152.

8. Gurupadayya, B. M.; Vishwajith, V.; Srujana, N.; World J. Chem. 2009, 4, 157.

9. Jayesh, G. P.; Ravindra, V. P.; Shobhana, K. M.; Biomed. Chromatogr. 2011, 25, 524.

10. Shubhangi, M. P.; Sunil, R. D.; J. Liq. Chromatogr. Relat. Technol. 2011, 34, 1664.

11. Alessandro, M.; Ernst, K.; Emanuele, M.; Anal. Chim. Acta 2008, 626, 89.

12. Aref, M. A.; Raoof, J. B.; Ojani, R.; Colloids Surf. B 2013, 109, 287.

13. Raoof, J. B.; Ojani, R.; Baghayeri, M.; Aref, M. A.; Anal. Methods 2012, 4, 157.

14. Lin, X.; Li, Y.; Biosens. Bioelectron. 2006, 22, 253.

15. Ghavami, R.; Salimi, A.; Navaee, A.; Biosens. Bioelectron. 2011, 26, 3864.

16. O’Regan, B.; Gratzel, M.; Nature 1991, 353, 737.

17. Macak, J. M.; Barczuk, P. J.; Tsuchiya, H.; Nowakowska, G. A.; Chojak, M.; Bauer, S.; Virtanen, S.; Kulesza P. J.; Schmuki, P.; Electrochem. Commun. 2005, 7, 1417.

18. Qingwen, L.; Yiming, W.; Guoan, L.; Mater. Sci. Eng. C 2000, 11,71 .

19. Li, G.; Qu, J.; Zhang, X.; Ge, J.; Water Res. 2006, 40, 213.

20. Lo, P. H.; Kumar, S. A.; Chen, S. M.; Colloids Surf. B 2008 , 66, 266.

21. Raoof, J. B.; Ojani, R.; Baghayeri, M.; Chin. J. Catal. 2011, $32,1685$.

22. Lunsford, S. K.; Choi, H.; Stinson, J.; Yeary, A.; Dionysiou, D. D.; Talanta 2007, 73, 172.

23. Mashhadizadeh, M. H.; Afshar, E.; Electrochim. Acta 2013, 87, 816.

24. Mashhadizadeh, M. H.; Refahati, R.; Amereh, E.; Anal. Bioanal. Electrochem. 2013, 5, 270.
25. Gharibi, H.; Kakaei, K.; Zhiani, M.; J. Phys. Chem. C 2010, $114,5233$.

26. Hassaninejad-Darzi, S. K.; Rahimnejad, M.; J. Iran. Chem. Soc. 2014, 11, 1047.

27. Jain, R.; Tiwarib, D. C.; Shrivastava, S.; Mater. Sci. Eng. B 2014, 185, 53.

28. Jain, R.; Sharma, R.; Yadav, R. K.; Shrivastava, R.; J. Electrochem. Soc. 2013, 160, 179.

29. Engin, C.; Yilmaz, S.; Saglikoglu, G.; Yagmur, S.; Sadikoglu, M.; Int. J. Electrochem. Sci. 2015, 10, 1916.

30. Madrakian, T.; Haghshenas, E.; Afkhami, A.; Sens. Actuators, B 2014, 193, 451.

31. Azizi, S. N.; Ghasemi, S.; Chiani, E.; Electrochim. Acta 2013, $88,463$.

32. Fleischmann, M.; Korinek, K.; Pletcher, D.; J. Electroanal. Chem. Interfacial Electrochem. 1971, 31, 39.

33. Laviron, E.; J. Electroanal. Chem. 1979, 101, 19.

34. Narayana, P. S.; Teradal, N. L.; Seetharamappa, J.; Satpati, A. K.; Anal. Methods 2015, 7, 3912.

35. Teixeira, J. G.; Veiga, A.; Carvalho, A. J. P.; Teixeira, D. M.; Electrochim. Acta 2013, 108, 51.

36. Cheemalapati, S.; Karuppiah, C.; Chen, S. M.; Ionics 2014, 20 , 1599.

37. Thirumoorthi, A.; Elango, K. P.; J. Chem. Sci. 2007, 119, 289.

38. Adams, R. N.; Electrochemistry at Solid Electrodes. Monographs in Electroanalytical Chemistry and Electrochemistry; Marcel Dekker: New York, 1969.

39. Haouas, K. B.; Tapsoba, I.; Benkhoud, M. L.; Boujlel, K.; J. Electroanal. Chem. 2004, 571, 241.

40. Taraszewska, J.; Rosłonek, G.; J. Electroanal. Chem. 1994, 364, 209.

41. Greef, R.; Peat, R.; Peter, L. M.; Pletcher, D.; Robinson, J.; Instrumental Methods in Electrochemistry; Ellis Horwood: Chichester, 1990.

42. Luo, H.; Shi, Z.; Li, N.; Gu, Z.; Zhuang, Q.; Anal. Chem. 2001, 73, 915.

43. Alessandro, M.; Ernst, K.; Emanuele M.; Anal. Chim. Acta 2008, 626, 89.

44. Lau, Y. Y.; Hanson, G. D.; Ichhpurani, N.; J. Chromatogr. B 1996, 683, 217.

45. Lavudu, P.; Rani, A. P.; Sekaran, C. B.; Kumar, K. S.; Ramesh, A.; Chem. Sci. J. 2012, 2012, CSJ49.

Submitted: February 11, 2016

Published online: June 28, 2016 